\title{
Synthesis of Bullvalenes: Classical Approaches and Recent Developments
}

\author{
Sofia Ferrer ${ }^{\mathrm{a}}$ \\ Antonio M. Echavarren*a,b (iD) \\ a Institute of Chemical Research of Catalonia (ICIQ), Barcelona Institute of \\ Science and Technology, Av. Països Catalans 16, 43007 Tarragona, Spain \\ b Departament de Química Analítica i Química Orgànica, Universitat Rovira i \\ Virgili, c. Marcel-lí Domingo s/n, 43007 Tarragona, Spain \\ aechavarren@iciq.es \\ Dedicated to the memory of Prof. Félix Serratosa, a pioneer of organic synthesis \\ in Spain \\ Published as part of the 50 Years SYNTHESIS - Golden Anniversary Issue
}

Received: 25.11.2018

Accepted: 28.11.2018

Published online: 14.01 .2019

DOI: 10.1055/s-0037-1611637; Art ID: ss-2018-z0791-sr

License terms: CC

Abstract The goal of this short review is to provide an overview of the different synthetic methodologies applied along the years for the synthesis of bullvalenes, prototypical fluxional molecules that were key in the understanding of valence tautomerism phenomena. Some interesting applications of these unique shapeshifting compounds are also presented.

1 Introduction

Classical Syntheses of Bullvalenes

Recent Developments in the Synthesis of Bullvalenes

Applications of Bullvalenes

Conclusion

Key words bullvalenes, fluxional, cage-like molecules, shapeshifting, degenerate isomers

\section{Introduction}

Fluxional molecules are dynamic structures that rapidly interchange between a number of constitutional isomers through low-energy rearrangements. ${ }^{1}$ These shapeshifting molecules have been crucial in the study of the fundamental concept of valence tautomerization. This phenomenon is based on the rapid rupture and formation of single and/or double bonds without migration of atoms or groups. A classical example of a fluxional molecule is bullvalene (1), with chemical formula $\mathrm{C}_{10} \mathrm{H}_{10}$; this is also one of the most popular examples of this type of molecule. This molecule can be seen as a tetracyclic cage-type structure formed by three units of 3,4-homotropylidene that undergo rapid [3.3] sigmatropic rearrangements (Scheme 1).,3
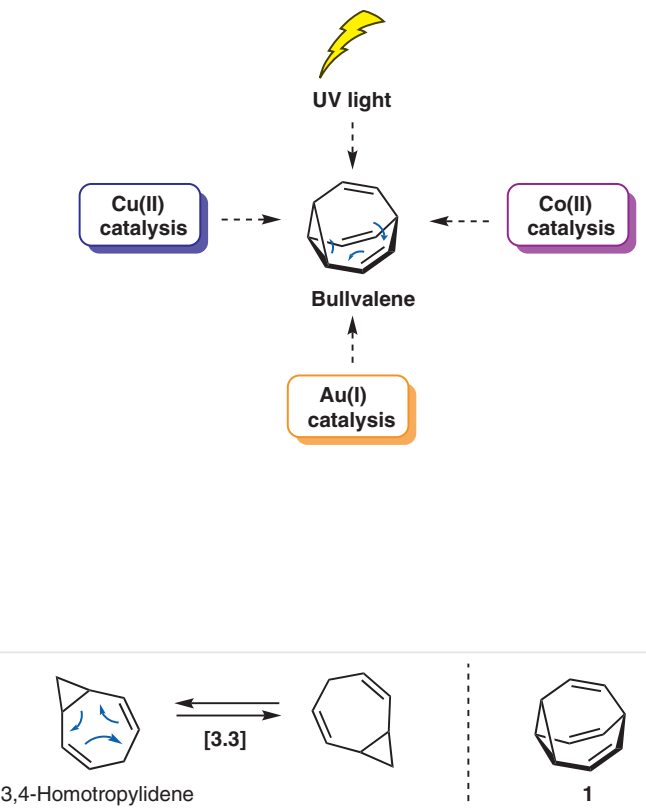

Scheme 1 3,4-Homotropylidene and bullvalene

A molecule such as bullvalene (1), with ten distinguishable positions and three symmetry axes, possesses $1,209,600$ degenerated interconvertible tautomers, thus it is a key structure in the understanding of valence tautomerization (Scheme 2). ${ }^{4-6} \mathrm{~A}$ lower number of constitutional isomers are possible for substituted bullvalenes. ${ }^{7-9}$

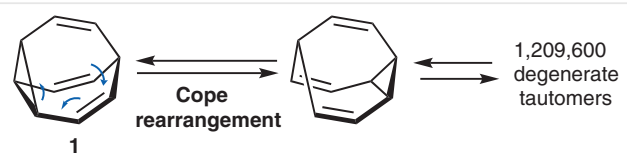

Scheme 2 Fluxionality in bullvalene

In bullvalene (1) all $\mathrm{C}-\mathrm{C}$ bonds are in continuous movement due to multiple and fast degenerated Cope rearrangements. As a consequence, all carbon and hydrogen atoms of the molecule are equivalent on the nuclear magnetic resonance timescale, consisting of a single broad signal in the ${ }^{1} \mathrm{H}$ NMR spectrum at room temperature and a sharp signal at high temperatures (ca. $120^{\circ} \mathrm{C}$ ) (Figure 1). However, at temperatures around $-60{ }^{\circ} \mathrm{C}$, the four aliphatic and the six olefinic protons of the molecule give rise to distinct signals. ${ }^{10}$

The structure and properties of bullvalene (1) were predicted by von Doering and Roth in 1963, ${ }^{3 a}$ as a part of a study on thermal rearrangements. These investigations led to the conclusion that the particular structure of bullvalene that forces its three 3,4-homotropylidene units to adopt a 


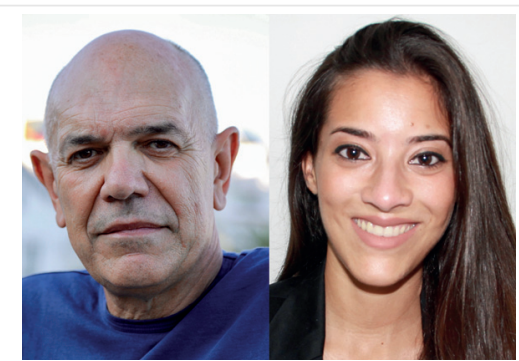

Antonio M. Echavarren received his Ph.D. at the Universidad Autónoma de Madrid (UAM, 1982). After a postdoctoral stays in Boston College and Colorado State University he joined the Institute of Organic Chemistry of the CSIC in Madrid. In 1992 he returned to the UAM as a Professor and in 2004 he moved to Tarragona as a Group Leader at the Institute of Chemical Research of Catalonia (ICIQ). He has been Liebig Lecturer (2006), Abbot Lecturer (University of Illinois at Urbana-Campaign, 2009), Schulich Visiting Professor (Technion, Haifa, 2011), Sir Robert Robinson Distinguished Lecturer (University of Liverpool, 2011), Novartis Lecturer in Organic Chemistry (Massachusetts Institute of Technology, 2015), and Kurt Alder Lecturer 2017 (University of Cologne). In 2012 he got a European Research Council Advanced Grant and in 2014 he was the president of the 49th EUCHEM Conference on Stereochemistry (Bürgenstock conference). Prof. Echavarren is a member of the International Advisory Board of Organic \& Biomolecular Chemistry, Chemical Society Reviews, Advanced Synthesis and Catalysis, and Organic Letters, member of the Editorial Board of Chemistry European Journal, and Associate Editor of Chemical Communications. He is a Fellow of the Royal Society of Chemistry. He received the 2004 Janssen-Cylag Award in Organic Chemistry and the 2010 Gold Medal of the Royal Spanish Chemical Society as well as an Arthur C. Cope Scholar Award from the ACS in 2015. Since January 2018, he is the President of the Spanish Royal Society of Chemistry.

Sofia Ferrer was born in Benissa (Alicante, Spain) in 1989. After a sixmonth stay in the University of Aarhus (Aarhus, Denmark) as an Erasmus student and a five-month relocation at Appalachian State University (North Carolina, USA) she received her B.Sc. degree in Chemistry from Universidad de Alicante (Alicante, Spain) in 2013. She obtained her M.Sc. at the Universitat Rovira i Virgili (Tarragona, Spain) in 2014. Since then she has been carrying out her Ph.D. studies under the supervision of Prof. Antonio Echavarren at the Institute of Chemical Research of Catalonia (ICIQ) working on the development of novel gold(I)-catalyzed reactions and their application to the synthesis of complex natural and unnatural products.

boatlike conformation would be ideal for fast and multiple degenerate Cope rearrangements assisted by strain release. ${ }^{11}$ Anecdotally, the name bullvalene was derived from the nickname of von Doering, known by his students as the 'bull', due to the feared and tough research group seminars, and was chosen to rhyme with fullvalene, another molecule of great interest for the group at that time.

Since the theoretical design of bullvalene (1) in 1963, ${ }^{\text {a }}$ this unique molecule has attracted the curiosity of the organic synthetic community. Significant synthetic efforts have led to the development of expedient syntheses of $\mathbf{1}$ that have constituted the basis of extensive studies in bullvalene chemistry and have enabled the preparation of many substituted derivatives. The constant evolution of synthetic methodology has allowed considerably shorten-
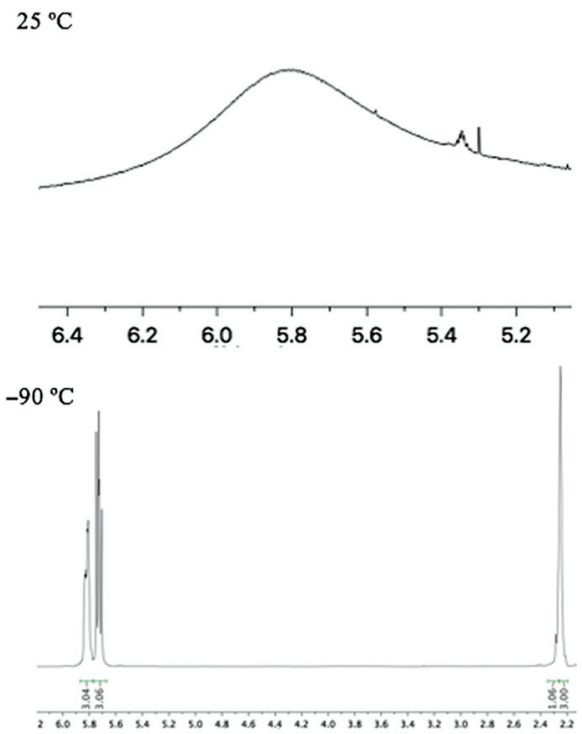

Figure 1 Image of variable temperature ${ }^{1} \mathrm{H}$ NMR spectra of bullvalene in $\mathrm{CDCl}_{3}$ at $25^{\circ} \mathrm{C}$ and in $\left(\mathrm{CD}_{3}\right)_{2} \mathrm{CO}$ at $-90^{\circ} \mathrm{C}$

ing of the preparation of $\mathbf{1}$ and its derivatives along the years, facilitating the access and exploration of these fluxional molecules.

\section{Classical Syntheses of Bullvalenes}

\subsection{Preparation of Bullvalene}

Shortly after the prediction of the structure and properties of bullvalene, this molecule was serendipitously obtained in 1963 by Schröder and co-workers while exploring the photochemistry of cyclooctatetraene dimers. ${ }^{4 a-c}$ Despite the low overall yield (6\%), this two-step synthesis of bullvalene (1), consisting of the dimerization of cyclooctatetraene (2) at $100{ }^{\circ} \mathrm{C}$ and subsequent photochemical opening of the dimer 3 (Scheme 3) with the consequential formation of benzene as byproduct, constitutes one of the shortest preparations of $\mathbf{1}$ to date.

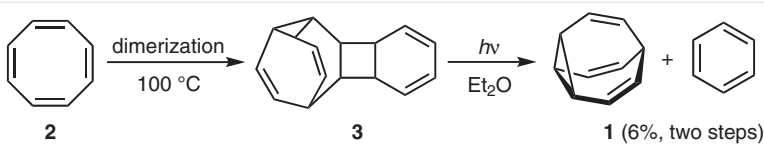

Scheme 3 The first synthesis of bullvalene (Schröder and co-workers)

In 1966, the von Doering group developed a different synthetic strategy for the preparation of bullvalene (1) via the UV irradiation of 4a,8a-dihydronaphthalene (5), prepared by thermal partial decomposition of the Nenitzescu hydrocarbon 4 at $301{ }^{\circ} \mathrm{C} .{ }^{12}$ Although short, this synthesis 
was impractical due to the formation of naphthalene and other undetermined products that were difficult to separate from $\mathbf{1}$ (Scheme 4).

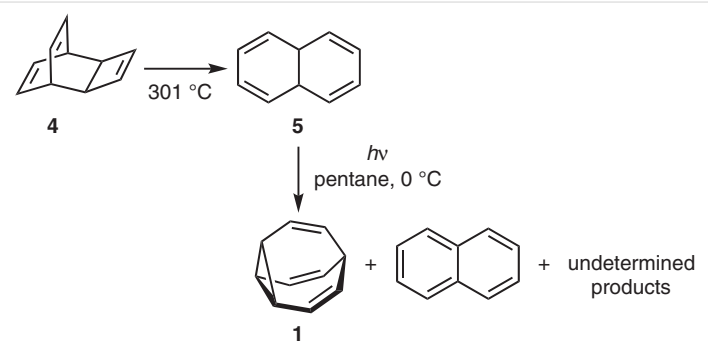

Scheme 4 Synthesis of bullvalene (von Doering group)

Another synthetic procedure designed by Jones and Scott was based on the UV irradiation of bicyclo[4.2.2]deca2,4,7,9-tetraene (8a) to afford 1 cleanly in 64\% yield. ${ }^{13}$ The main drawback of this protocol was the tedious synthesis of 8a, which was also low yielding. ${ }^{4}$ This preparation commenced with $\mathrm{Cu}(\mathrm{II})$-promoted thermal decomposition of diazoacetic ester in the presence of cyclooctatetraene (2) to afford methyl bicyclo[6.1.0]nona-2,4,6-triene-9-carboxylate (6) (Scheme 5). Conversion of $\mathbf{6}$ into the sodium salt of tosylhydrazone $\mathbf{7}$ was accomplished via the corresponding acid, generation of the acid chloride, reduction to the aldehyde, and formation of the tosylhydrazone. Thermal decomposition of the tosylhydrazone sodium salt 7 at 90-120 ${ }^{\circ} \mathrm{C}$ led to a complex mixture of $\mathrm{C}_{10} \mathrm{H}_{10}$ products including $\mathbf{8 a}$, which was obtained in $38 \%$ yield.

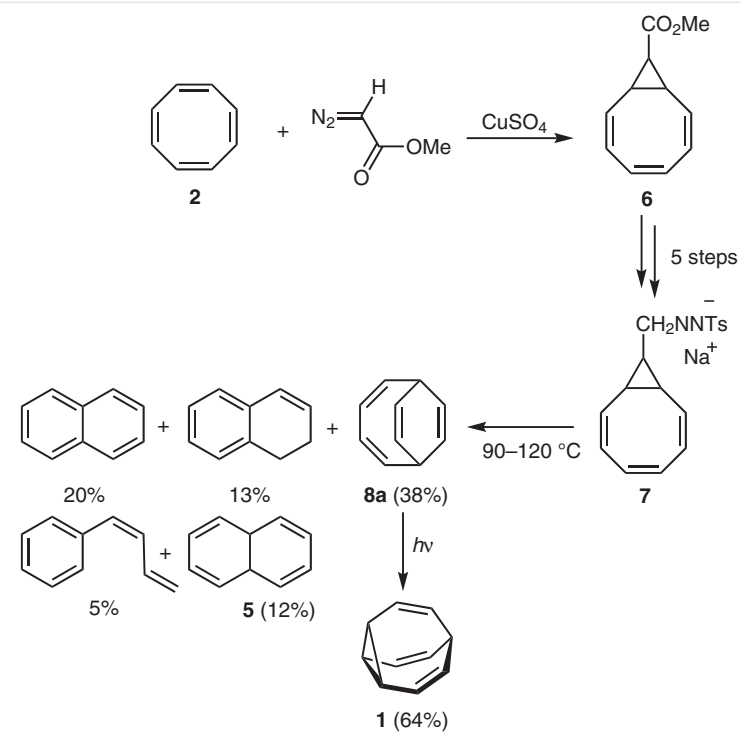

Scheme 5 Synthesis of bullvalene (Jones and Scott)

With the aim of improving his first synthetic design of bullvalene (1), the von Doering group envisioned a new synthetic route to $\mathbf{1}$ through barbaralone (9a) and bullva- lone (10a), (Scheme 6). ${ }^{3 b}$ The aforementioned molecules 9a and 10a also undergo low energy Cope rearrangements, leading to two constitutional isomers respectively. ${ }^{6 c, 15}$

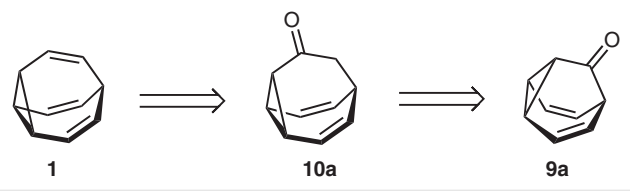

Scheme 6 Retrosynthesis of bullvalene through barbaralone and bullvalone (von Doering group)

In the case of barbaralone (9a), the two possible isomers are degenerated, whereas for bullvalone (10a), the one carbon homologue of $\mathbf{9 a}$, the equilibrium is dominated by the most stable isomer (Scheme 7).
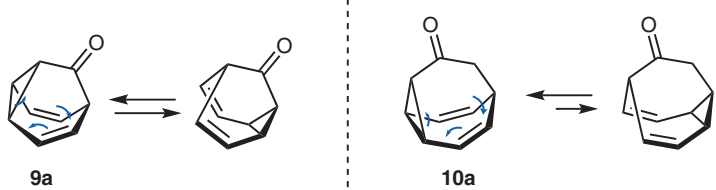

Scheme 7 Fluxionality in barbaralone and bullvalone

This synthesis, 1967, started with the Buchner reaction of ethyl diazoacetate with benzene under harsh conditions and long reaction times to give cycloheptatriene $\mathbf{1 1}$ (Scheme 8). ${ }^{3 \mathrm{~b}}$ Hydrolysis of the ester in $\mathbf{1 1}$ to the carboxylic acid, followed by reaction with $\mathrm{SOCl}_{2}$ led to the acyl chloride 13, which reacted with diazomethane to afford diazomethyl ketone 14. Treatment of $\mathbf{1 4}$ with $\mathrm{CuSO}_{4}$ in a mixture of benzene/hexane under reflux led to barbaralone (9a). In 1998, the Buchner reaction was improved by Johnston and co-workers by using a Rh salt as the catalyst, which allowed the temperature to be decreased to $45{ }^{\circ} \mathrm{C}$ and the reaction time reduced to $8-10$ hours. ${ }^{16}$ One-carbon homologation of barbaralone (9a) with diazomethane led to bullvalone (10a) in $24 \%$ yield, along with isomeric aldehyde 10a' (25\% yield). Reduction of the ketone functionality of 10a with $\mathrm{NaBH}_{4}$ gave 15, which was acetylated with acetic anhydride in pyridine at $130{ }^{\circ} \mathrm{C}$ to form $\mathbf{1 6}$ (40\%, two steps). The final step involved a challenging pyrolysis of $\mathbf{1 6}$ at very high temperature $\left(345^{\circ} \mathrm{C}\right)$ to afford bullvalene (1).

In 1972, a new synthesis of bullvalene (1) was designed by the Serratosa group (Scheme 9). ${ }^{17}$ This route allowed the preparation of $\mathbf{1}$ in three steps from tris(3-diazo-2-oxopropyl)methane [methane(tri- $\alpha$-diazoacetone); 21]. Tris-diazoketone $\mathbf{2 1}$ was synthesized in five steps from methyl ester $\mathbf{1 7}$ by Wittig reaction, reduction of the with Adams' catalyst, hydrolysis of the esters, conversion into the acyl chloride with $\mathrm{PCl}_{5}$, and reaction with diazomethane. ${ }^{18}$ Reaction of $\mathbf{2 1}$ in the presence of $\mathrm{CuSO}_{4}$ in xylene at reflux under high dilution conditions afforded tricyclo[3.3.2.02,8 decane- 


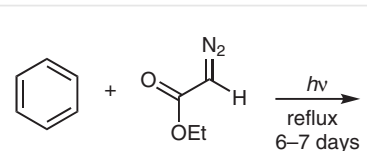<smiles>CCOC(=O)C1C=CC#CC=C1</smiles><smiles>O=C(O)c1ccccc1</smiles>
$\mathrm{SOCl}_{2}$

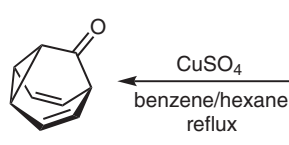

9a $\mathrm{CH}_{2} \mathrm{~N}_{2}$<smiles>CCOC(=O)C1C2C=CC(CC2)C1C(=O)OCC</smiles>

10a' $(24 \%)$

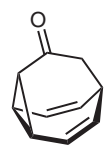

10a $(25 \%)$
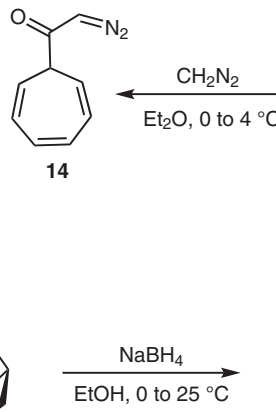

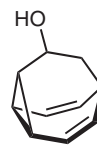

15

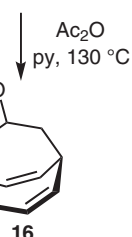

Scheme 8 Synthesis of bullvalene through barbaralone and bullvalone (von Doering group)

3,7,9-trione ('bullvalenetrione', 22) in ca. $2 \%$ yield. The yield of this reaction could be improved to $4 \%$ by employing soluble copper chelates as catalysts. Despite the low yields, this is a remarkable transformation in which three $\mathrm{C}-\mathrm{C}$ bonds are formed. Reaction of $\mathbf{2 2}$ with $p$-toluenesulfonyl hydrazide led to tris-tosylhydrazone $\mathbf{2 3}$, which was converted into bullvalene (1) in $20 \%$ yield by treatment with excess methyllithium under Shapiro reaction conditions. ${ }^{19}$ Overall, this synthesis of $\mathbf{1}$ was completed in 8 steps and ca. $0.3 \%$ overall yield.

The Serratosa group developed another route to $\mathbf{1}$ inspired by the procedure of the von Doering group presented in Scheme $8^{3 \mathrm{~b}}$ but applying some of the reactions employed in their first approach. ${ }^{17}$ In this route, barbaralone (9a) was prepared more efficiently from 14 by a modified procedure using copper(II) acetylacetonate as soluble copper catalyst (Scheme 10) ${ }^{20}$ Homologation of 9a with diazomethane led to $\mathbf{1 0 a}$, which reacted with $p$-toluenesulfonyl hydrazide in acetic acid to give tosylhydrazone $\mathbf{2 4}$ in $70 \%$ yield through an unexpected rearrangement (see mechanism in Scheme 10). Anionic fragmentation of the tosylhydrazone $\mathbf{2 4}$ with excess methyllithium gave 8a in $36 \%$ yield. Hydrocarbon $\mathbf{8 a}$, reported by Jones and Scott in their approach to bullvalene (1) (see Scheme 5), ${ }^{13}$ was converted into $\mathbf{1}$ by UV irradiation in $82 \%$ yield. In this way, $\mathbf{1}$ was prepared in 9 steps in ca. $2 \%$ overall yield.

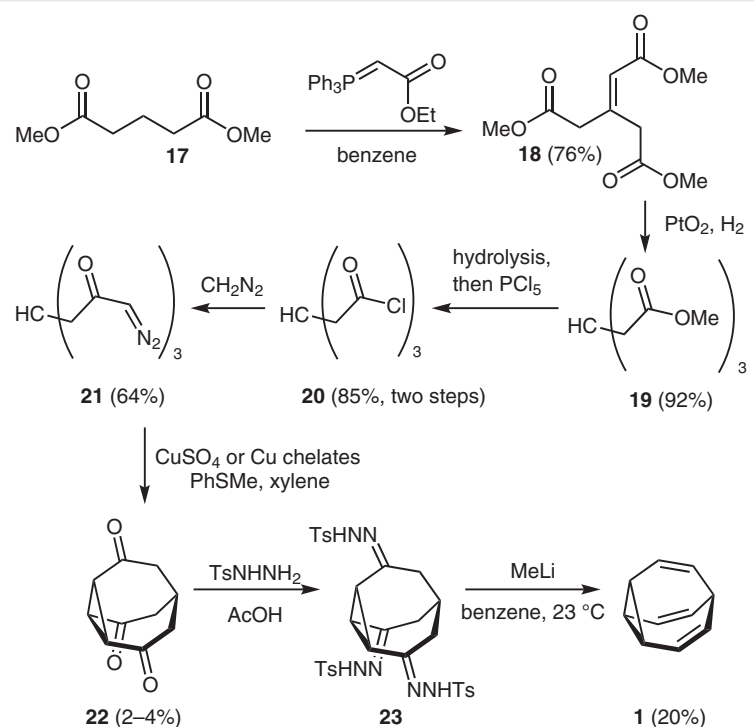

Scheme 9 Synthesis of bullvalene from 'bullvalenetrione' (Serratosa group)
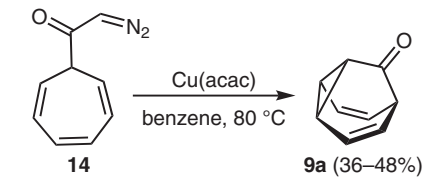

$\mathrm{CH}_{2} \mathrm{~N}_{2}$
$\mathrm{Et}_{2} \mathrm{O}, 0$ to $4^{\circ} \mathrm{C}$

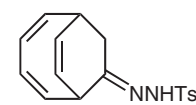

$24(70 \%)$ $\downarrow \begin{gathered}\text { MeLi } \\ \text { benzene, } 0^{\circ} \mathrm{C}\end{gathered}$

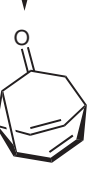

10a (24\%)

10a' (34\%)
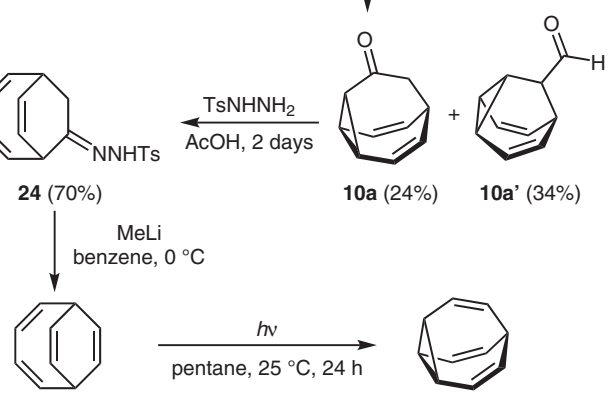

$8 \mathbf{a}(36 \%)$

$1(82 \%)$

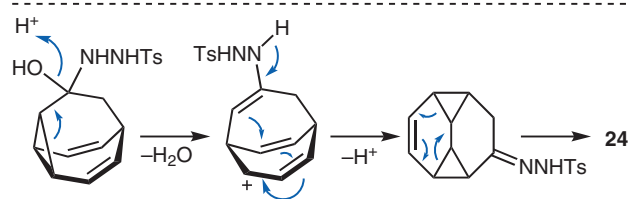

Scheme 10 Synthesis of bullvalene from barbaralone (Serratosa group)

\subsection{Syntheses of Substituted Bullvalenes}

During the 1970s, progress made in the synthesis of bullvalene (1) led to numerous studies on its fluxional behavior along with the preparation of a variety of mono- and polysubstituted bullvalenes. The synthesis of substituted 


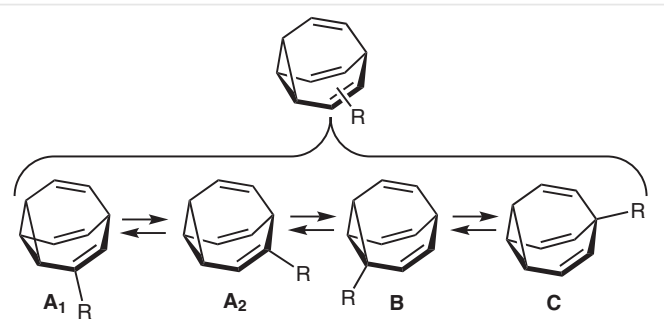

Scheme 12 The four possible positional isomers for monosubstituted bullvalenes

bullvalenes was accompanied by interesting investigations, mainly based on NMR studies, on the study of their equilibria. ${ }^{21}$ Most substituted bullvalenes were synthesized from the parent unsubstituted bullvalene (1). Monosubstituted bullvalenes were normally derived from a common bromobullvalene intermediate $\mathbf{2 5}$ usually prepared in two steps by dibromination of $\mathbf{1}$ with $\mathrm{Br}_{2}$ followed by dehydrobromination with KOtBu (Scheme 11). ${ }^{22}$ Chlorobullvalene (26) could be also synthesized similarly by chlorination with $\mathrm{SO}_{2} \mathrm{Cl}_{2}$ and subsequent elimination of $\mathrm{HCl}$ by reaction with KOtBu (Scheme 11). ${ }^{21}$
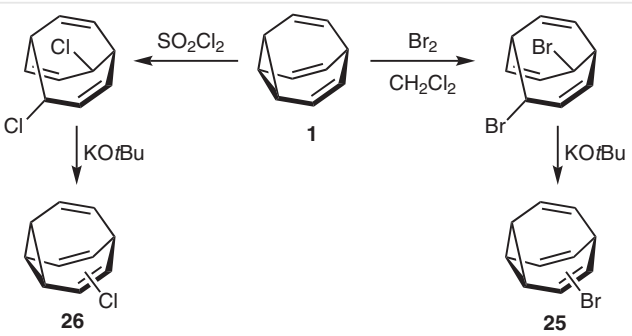

Scheme 11 Preparation of bromobullvalene and chlorobullvalene from bullvalene

Monosubstituted bullvalenes possess around $1.2 \times 10^{6}$ valence isomers, but in contrast to the parent bullvalene (1), all these isomers are not structurally equivalent. For monosubstituted bullvalenes there are four possible positional isomers $\mathbf{A}_{1}, \mathbf{A}_{\mathbf{2}}, \mathbf{B}$, and $\mathbf{C}$ (Scheme 12), which can be interconverted at room temperature by Cope rearrangements. ${ }^{21}$ The equilibrium between these four positional isomers is dynamic at high temperatures, although it can be frozen at low temperatures. ${ }^{4 \mathrm{~d}, 22}$ The equilibrium composition is influenced by the nature of the substituent R. ${ }^{22} \mathrm{Al}-$ though in most cases the substituent preferentially occupies an olefinic position $\left(\mathbf{A}_{\mathbf{1}}\right.$ and/or $\left.\mathbf{A}_{\mathbf{2}}\right)$, there are some exceptions. Thus, the fluoro group stays preferentially at the methine carbon (C), ${ }^{21}$ and hydroxymethyl $\left(\mathrm{CH}_{2} \mathrm{OH}\right)$, methoxymethyl $\left(\mathrm{CH}_{2} \mathrm{OMe}\right)$, and acetoxymethyl $\left(\mathrm{CH}_{2} \mathrm{OAc}\right)$ groups show a slight preference for the aliphatic positions on bullvalene $(\mathbf{B}){ }^{23}$
Phenylbullvalene $(\mathbf{2 7})^{24}$ and methylbullvalene $(\mathbf{2 8})^{25}$ were prepared from bromobullvalene (25) by reaction with $\mathrm{Ph}_{2} \mathrm{CuLi}$ and $\mathrm{Me}_{2} \mathrm{CuLi}$, respectively (Scheme 13). Phenylbullvalene (27) was found to be in a 3:1 equilibrium between the 4- and 3-substituted isomers, ${ }^{24}$ whereas methylbullvalene (28) appeared to be in a 1.2:1 equilibrium between the 4 - and 3-substituted isomers. ${ }^{25}$ Alternatively, methylbullvalene (28) was also synthesized by addition of methylmagnesium bromide and $\mathrm{CoCl}_{2}$ to bromobullvalene. ${ }^{21}$ The preparation of (alkylthio)bullvalene $\mathbf{2 9}$ was achieved by refluxing bromobullvalene (25) with copper(I) mercaptides in pyridine and quinoline..$^{26}$

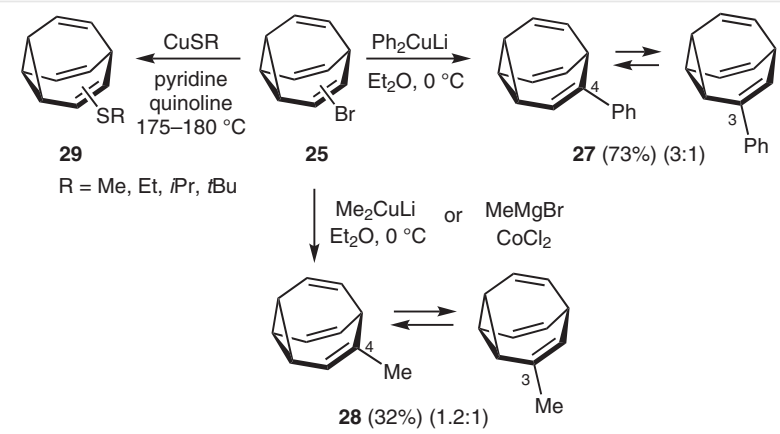

Scheme 13 Synthesis of phenylbullvalene, methylbullvalene, and thioethers of bullvalene

The bullvalene Grignard derivative $\mathbf{3 0}$ was prepared by reaction of $\mathbf{2 5}$ with magnesium (Scheme 14). ${ }^{27}$ Reagent $\mathbf{3 0}$ was further transformed into bullvalenecarboxylic acid (31) by reaction with $\mathrm{CO}_{2}$, dibullvalene (32) by reaction with bromobullvalene (25) in the presence of $\mathrm{CoCl}_{2}$, and iodobullvalene (33) by reaction with $\mathrm{I}_{2}{ }^{21,27}$ Compound $\mathbf{3 3}$ was used as starting material for the synthesis of fluorobullvalene (34) by reaction with $\mathrm{AgF}^{21}$

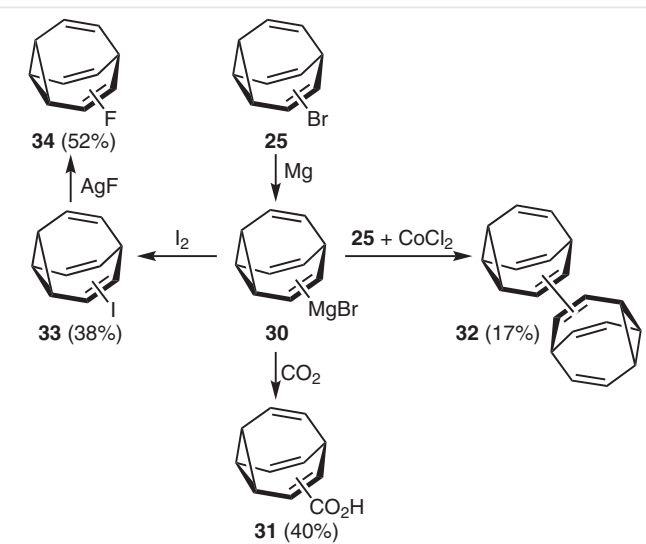

Scheme 14 Synthesis of monosubstituted bullvalenes derived from bullvalene Grignard compound 
Alkoxybullvalenes (36) with methoxy, ethoxy, isopropoxy, and tert-butoxy groups have been obtained by addition of the corresponding potassium alkoxides to bromobullvalene (25).22 These reactions presumably proceed through intriguing dehydrobullvalene intermediate $\mathbf{3 5}$ (Scheme 15).22 All substituted bullvalenes showed temperature-dependent NMR spectra. ${ }^{21}$

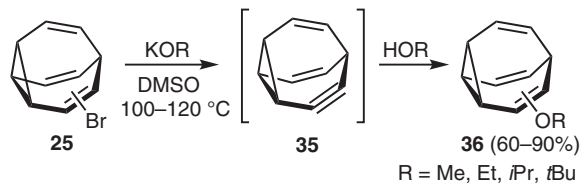

Scheme 15 Preparation of alkoxybullvalenes

Disubstituted bullvalenes have been commonly prepared from dibromobullvalene (37), obtained from bromobullvalene (25) by another sequence of dibromination/dehydrobromination (Scheme 16). ${ }^{28}$ Interestingly, when dry $\mathrm{KO} \mathrm{tBu}$ in benzene was used instead of KOtBu in $t \mathrm{BuOH}$ and benzene in the dehydrobromination, di-tert-butoxybullvalene (38) was obtained. ${ }^{21}$

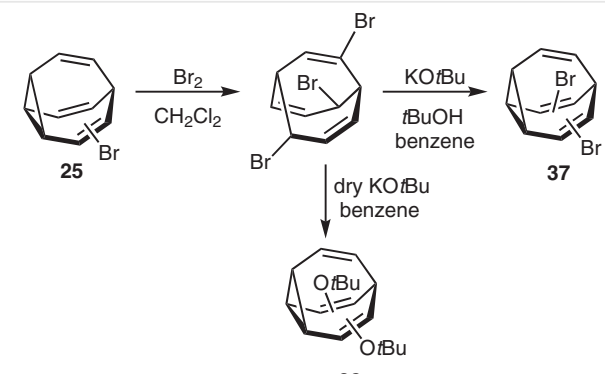

38

Scheme 16 Preparation of dibromobullvalene

A wide range of disubstituted bullvalenes with identical substituents were obtained by functional group transformations in dibromobullvalene (37). ${ }^{21,28,29}$ Reaction of $\mathbf{3 7}$ with $\mathrm{NaCu}(\mathrm{CN})_{2}$ led to dicyanobullvalene (39), which was further transformed by hydrolysis into bullvalenedicarboxylic acid (40) (Scheme 17). Reaction of $\mathbf{4 0}$ with diazomethane led to the formation of dimethyl bullvalenedicarboxylate (41). ${ }^{30}$ Bullvalenedicarbaldehyde (42) was obtained by reduction of the cyano groups in $\mathbf{3 9}$ with DIBAL-H. Further reduction of the aldehyde groups in $\mathbf{4 2}$ using $\mathrm{LiAlH}_{4}$ afforded bullvalenediol (43). On the other hand, reaction of $\mathbf{3 7}$ with $\mathrm{Me}_{2} \mathrm{CuLi}$ or $\mathrm{Ph}_{2} \mathrm{CuLi}$ gave dimethylbullvalene (44), ${ }^{25}$ as a 2.3:3.3:1 mixture of valence, and diphenylbullvalene (45), ${ }^{24}$ as a 7.6:5.7:1 mixture of 4,5-, 3,5-, and 3,7- disubstituted isomers.

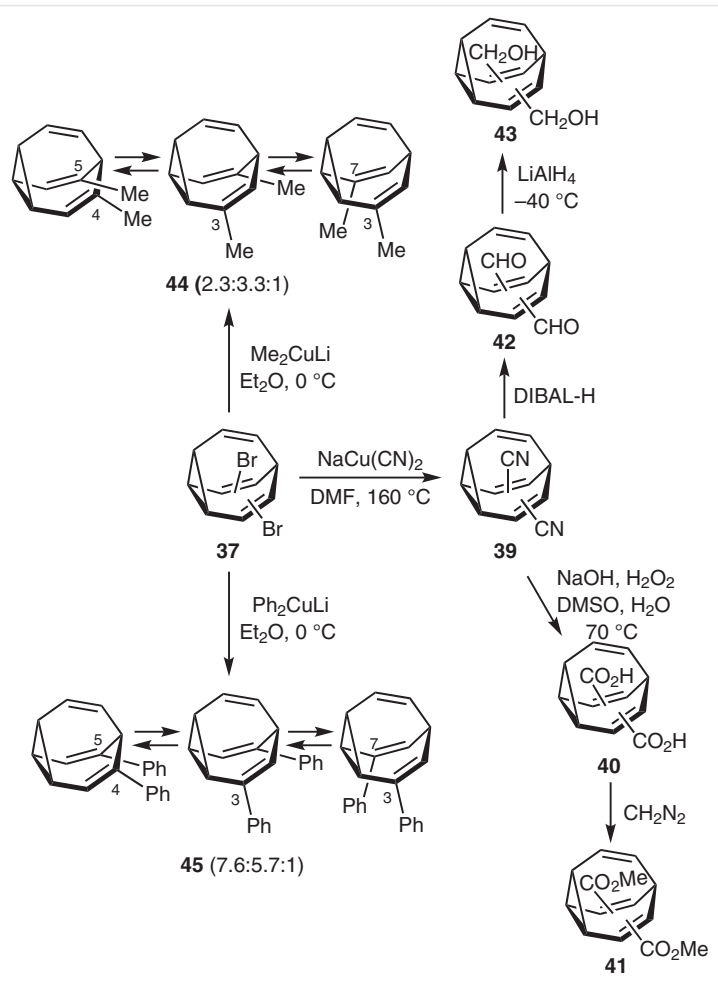

Scheme 17 Synthesis of disubstituted bullvalenes

A different procedure for the synthesis of dimethyl bullvalenedicarboxylate (41) consisted of the irradiation of dimethyl cis-4a,8a-dihydronaphthalene-4a,8a-dicarboxylate $\left(\mathbf{5}^{\prime}\right)$ in methanol by a low-pressure mercury lamp (Scheme 18). ${ }^{30}$ This transformation was mechanistically related to that found in the synthesis of $\mathbf{1}$ by Jones and Scott (see Scheme 5). ${ }^{13}$

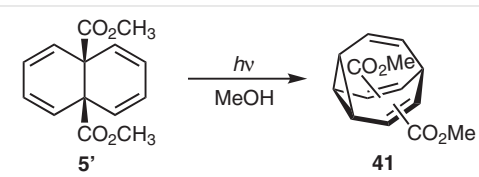

Scheme 18 Alternative preparation of dimethyl bullvalenedicarboxylate

Diphenylbullvalene (45) was alternatively prepared by reaction of tricarbonylcyclooctatetraeneiron $\left(\mathbf{2}^{\prime}\right)$ with diphenylacetylene at high temperatures (ca. $165^{\circ} \mathrm{C}$ ) to form 8b, followed by UV irradiation (Scheme 19). ${ }^{31}$

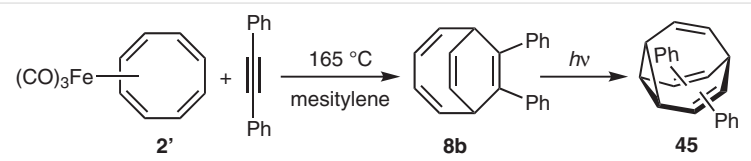

Scheme 19 Alternative preparation of diphenylbullvalene 
Disubstituted bullvalenes bearing two different substituents have also been synthesized. The most common approach is based on the monosubstitution of one bromine atom in dibromobullvalene (37) by a cyano group through reaction with $\mathrm{NaCu}(\mathrm{CN})_{2}$ leading to bromocyanobullvalene (46) (Scheme 20).21,32 Further reduction of the cyano group in 46 with DIBAL-H afforded bromobullvalenecarbaldehyde (47), which was reduced with $\mathrm{LiAlH}_{4}$ to bromobullvalenol (48). Derivatives $49,50,{ }^{31}$ and $\mathbf{5 1}{ }^{26}$ were similarly obtained.

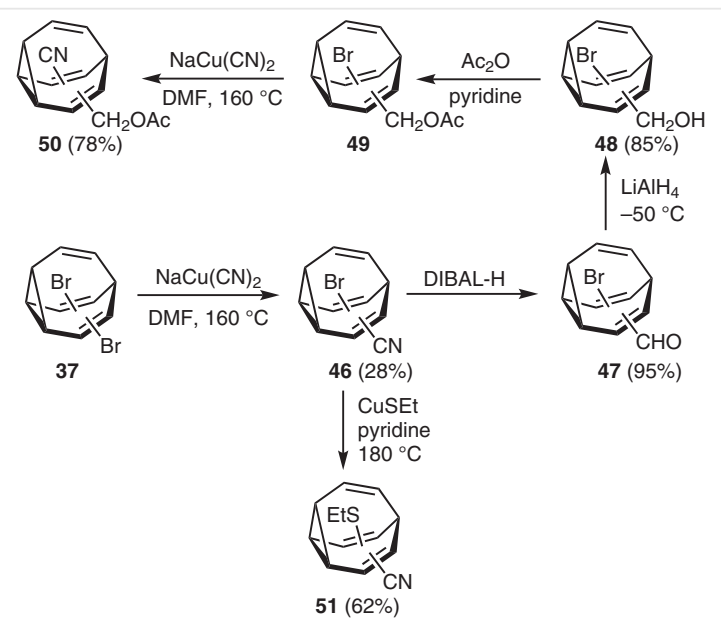

Scheme 20 Synthesis of differently disubstituted bullvalenes from dibromobullvalene

A different procedure for the synthesis of differently disubstituted bullvalenes involves the bromination/dehydrobromination of methylbullvalene (28) to afford bromo(methyl)bullvalene (52) (Scheme 21). The bromine in $\mathbf{5 2}$ was further substituted by a cyano group through reaction with $\mathrm{NaCu}(\mathrm{CN})_{2}$ to give cyano(methyl)bullvalene (53). ${ }^{31} \mathrm{Hy}-$ drolysis of the cyano moiety to the carboxylic acid and subsequent reaction with diazomethane led to methyl methylbullvalenecarboxylate (54).

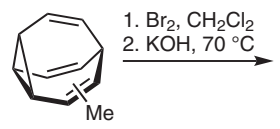

28

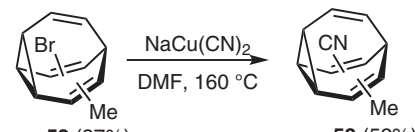

$52(37 \%)$

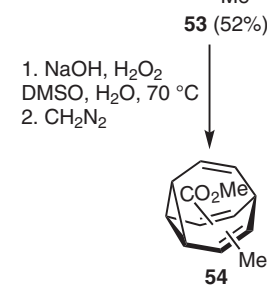

Scheme 21 Synthesis of differently disubstituted bullvalenes from methylbullvalene

On the other hand, bromofluorobullvalene (55) was prepared from fluorobullvalene (34) by bromination/dehydrobromination (Scheme 22). ${ }^{21}$

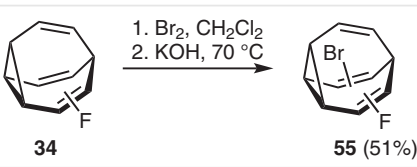

Scheme 22 Synthesis of bromofluorobullvalene from fluorobullvalene

A variety of fused disubstituted bullvalenes have been obtained by Diels-Alder reaction between the dehydrobullvalene intermediate $\mathbf{3 5}$, formed by reaction of bromobullvalene (25) with potassium alkoxides, and various dienes such as furan, 1,3-diphenylisobenzofuran (57), and tetraphenylcyclopentadienone $\mathbf{5 8}$ (Scheme 23). ${ }^{21,23}$ The expected direct Diels-Alder adducts $\mathbf{5 6}$ and $\mathbf{5 7 a}$, formed by reaction of $\mathbf{3 5}$ with furan and 57, respectively, were not observed due to their high strain. Instead, these adducts undergo rapid rearrangement to the more stable isomers $\mathbf{5 6 \mathbf { b }}$ and $\mathbf{5 7 b}$. Products $\mathbf{5 6 b}, \mathbf{5 7 b}$, and $\mathbf{5 9}$ showed temperature-dependent NMR spectra, evidencing their dynamic situation. ${ }^{21}$

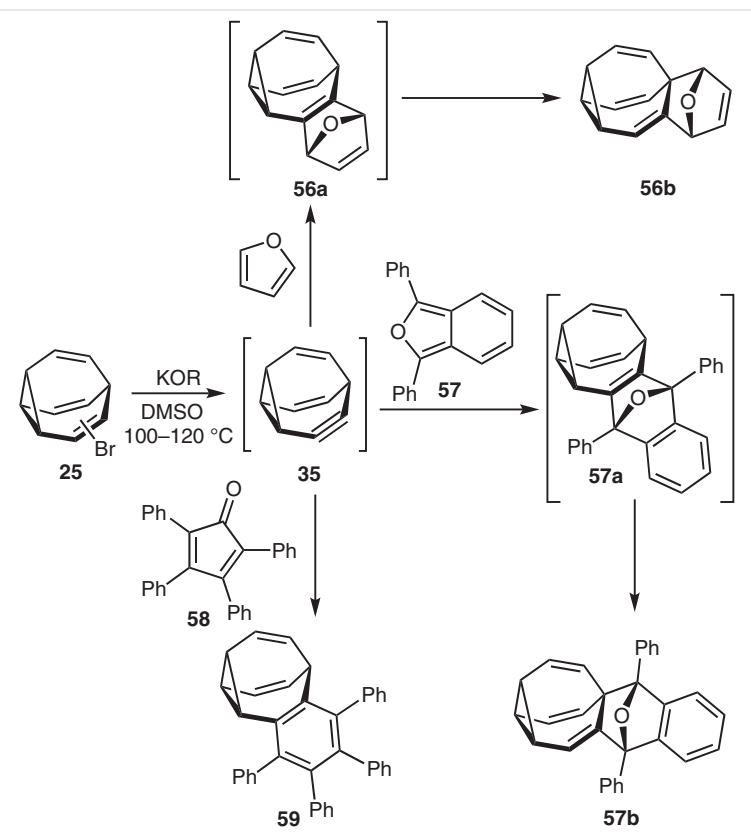

Scheme 23 Synthesis of fused disubstituted bullvalenes

Different trisubstituted bullvalenes were synthesized from parent tribromobullvalene $(\mathbf{6 0})$, prepared by bromination/dehydrobromination of dibromobullvalene (37). Reaction of $\mathbf{6 0}$ with $\mathrm{Me}_{2} \mathrm{CuLi}$ led to trimethylbullvalene (61), whereas treatment with $\mathrm{Ph}_{2} \mathrm{CuLi}$ afforded triphenylbullvalene (62), which was found in a 1:1.96:1.04 equilibrium between the 4,5,10-, 4,5,9-, and 3,7,10-isomers (Scheme 24)..$^{24}$

The same bromination/dehydrobromination sequence was employed for the synthesis of tetra- (63), penta- (66), and hexabromobullvalenes (68) (Scheme 25). ${ }^{8}$ Slower rearrangements were observed for pentabromobullvalene (66), 


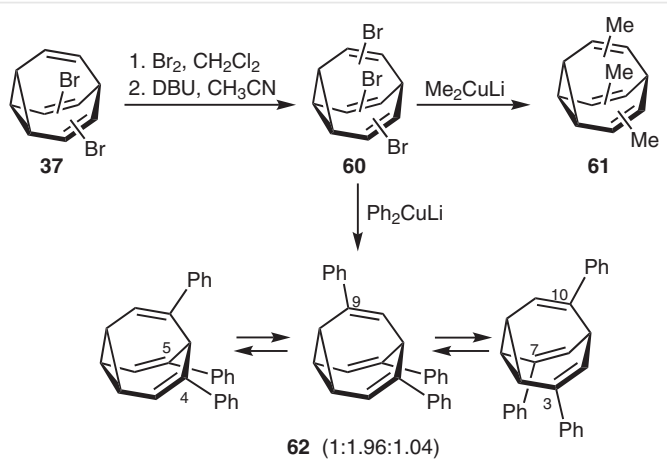

Scheme 24 Synthesis of trisubstituted bullvalenes

whereas no fluxional behavior was recognized in hexabromobullvalene (68), which was obtained as a single isomer. ${ }^{8 b}$ Tetramethylbullvalene (64) was formed by reaction of tetrabromobullvalene (63) with $\mathrm{Me}_{2} \mathrm{CuLi}^{25}$ Tetraphenylbullvalene (65), obtained by reaction of 63 with $\mathrm{Ph}_{2} \mathrm{CuLi}$ was found to be in a 4.2:5.9:1 equilibrium between the 1,4,5,10-, 1,3,5,10-, and 1,3,7,10-isomers. ${ }^{24}$ Penta- (67) and hexaphenylbullvalenes (69) were similarly prepared. As in the case of hexabromobullvalene (68), in hexaphenylbullvalene (69) the fluxional behavior was lost. ${ }^{24}$

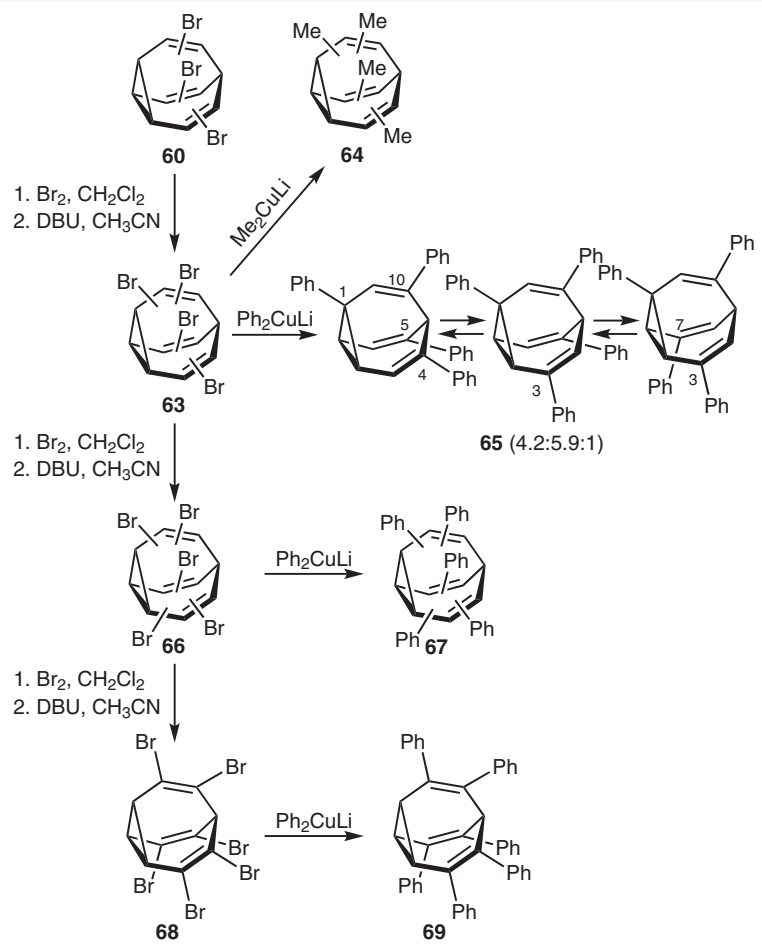

Scheme 25 Synthesis of tetra-, penta-, and hexasubstituted bullvalenes

\section{Recent Developments in the Synthesis of Bullvalenes}

The constant development in the field of synthetic organic along with the discovery of novel reactivities and methodologies has enabled ingenious new syntheses of bullvalene and highly substituted bullvalenes. An innovative syntheses of substituted bullvalenes has been developed by the Bode group, finding interesting applications of the corresponding products in supramolecular adaptive binding and sensing. ${ }^{9 a, b, 33 a, d}$ In this bullvalene synthesis, cycloheptanone (70) was used as the starting material (Scheme 26). Protection of cycloheptanone (70) with ethylene glycol gave acetal 71, which then was subjected to dibromination to give 72. Bromide elimination and acid hydrolysis provided cycloheptadienone $\mathbf{7 3}$, which underwent Mukaiyama-Michael addition of silyl enol ether $\mathbf{7 4}$ to give enone $\mathbf{7 5}$. Enedione $\mathbf{7 6}$ was obtained from $\mathbf{7 5}$ by allylic oxidation of $\mathbf{7 5}$ with diacetoxyiodobenzene and tert-butyl hydroperoxide. Conversion of $\mathbf{7 6}$ into the carboxylic acid $\mathbf{7 7}$ by treatment with trifluoroacetic acid, followed by reaction with tetrahydrothiophene-derived sulfur ylide $\mathbf{7 8}$, via a mixed anhydride, gave product $\mathbf{7 9}$, which was treated with

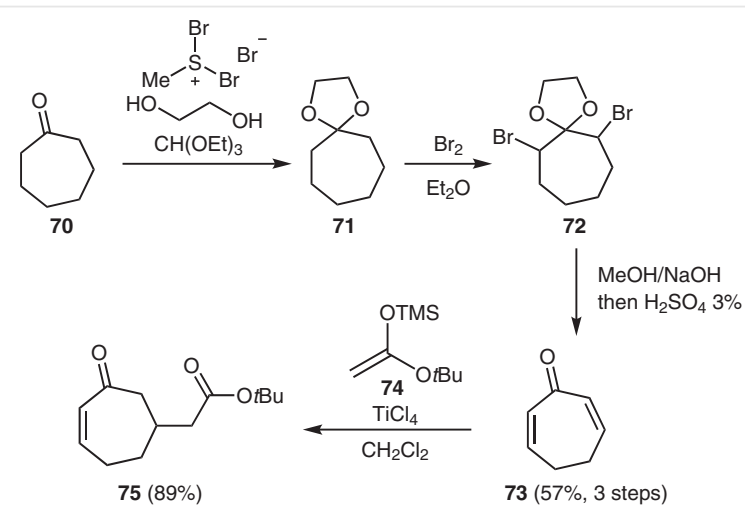

$\downarrow$ NBS, AIBN, DCE, $69^{\circ} \mathrm{C}$, then NMO, 4 A MS
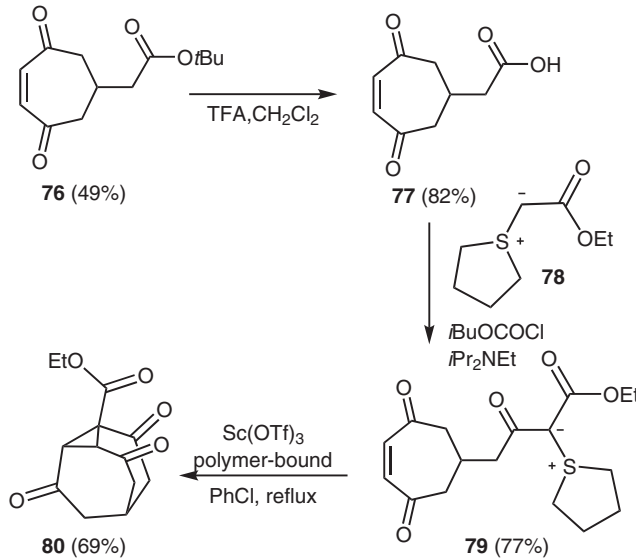

Scheme 26 Synthesis of a key triketone 
scandium triflate to trigger the intramolecular cyclopropanation that provided triketone $\mathbf{8 0}$, a key intermediate for further functionalizations.

Triketone $\mathbf{8 0}$ was transformed to diallylbullvalene $\mathbf{8 4}$ in three steps (Scheme 27). ${ }^{9 a, b, 33 a}$ Addition of allylmagnesium bromide to 80 afforded two diastereomeric diols, meso 81a and chiral 81b. Meso 81a was transformed into diallylbullvalone $\mathbf{8 2}$ by treatment with pyridine and thionyl chloride. The same reaction conditions applied to chiral $\mathbf{8 1 b}$ led to furan product 83. On the other hand, treatment of chiral 81b with diisopropylethylamine and thionyl chloride followed by pyridine provided $\mathbf{8 2}$. Finally, enolization of diallylbullvalone 82 and trapping of the enolate with isobutyl chloroformate gave diallylbullvalene $\mathbf{8 4}$. Therefore, tetrasubstituted bullvalene $\mathbf{8 4}$, with three different substituents and 840 possible interconvertible constitutional isomers, was obtained in 11 steps from cycloheptanone (70). Diallylbullvalene 84 constitutes a versatile intermediate whose two allyl moieties can be further employed for the attachment of other relevant functional groups.

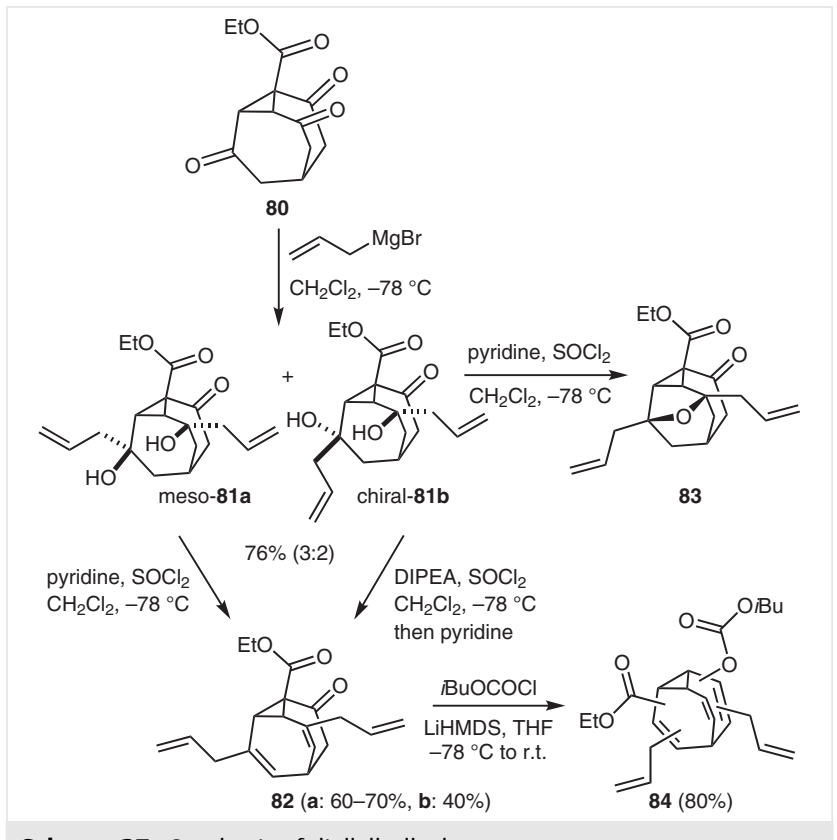

Scheme 27 Synthesis of diallylbullvalene

Since 2000, gold(I) catalysis has emerged as a powerful tool for the construction of molecular complexity from simple substrates. ${ }^{34}$ The ability of cationic gold(I) complexes to promote a wide variety of enyne cyclizations along with the versatility of the intermediates accessed through these transformations has been utilized to develop expedient and efficient synthesis of bullvalene and substituted bullvalenes through the fluxional molecules barbaralone (9a) and bullvalone (10a) from readily available 7-ethynylcyclohepta1,3,5-trienes (85) (Scheme 28). ${ }^{35}$

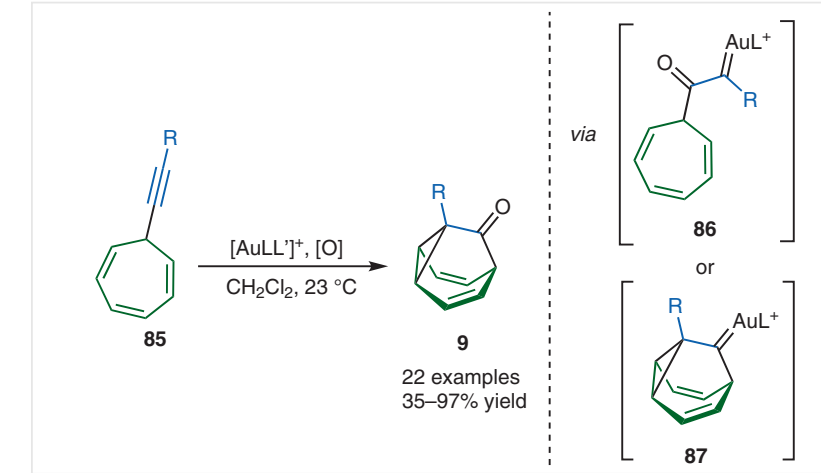

Scheme 28 Gold(I)-catalyzed access to barbaralones

This new approach relies on a gold(I)-catalyzed oxidative cyclization of $\mathbf{8 5}$ in the presence of external oxidants such as diphenyl sulfoxide or pyridine $\mathrm{N}$-oxides, to afford barbaralone (9a) and other 1-substituted barbaralones under mild conditions and good to excellent yields (Scheme 28)..$^{35}$ The barbaralone synthesis proceeds by activation of the alkyne in 85 by gold(I), followed by attack of the external oxidant to form $\alpha$-oxo gold(I) carbene 86, which then undergoes intramolecular cyclopropanation to give barbaralone $\mathbf{9}$. This transformation can be also seen as a gold(I)catalyzed cyclization of 1,6-enyne $\mathbf{8 5}$ to afford gold(I) carbene 87 followed by oxidation.

This new two-step approach to barbaralones constitutes one of the shortest, mildest, and most efficient synthesis of barbaralones 9 to date. Substrates 85 can be prepared in one step from the corresponding alkynes and commercially available tropylium tetrafluoroborate (Scheme 29). Reaction of 85a and 85b in the presence of gold(I) catalyst [IP$\mathrm{rAuNCMe}]^{+} \mathrm{SbF}_{6}{ }^{-}$and diphenyl sulfoxide as external oxidant

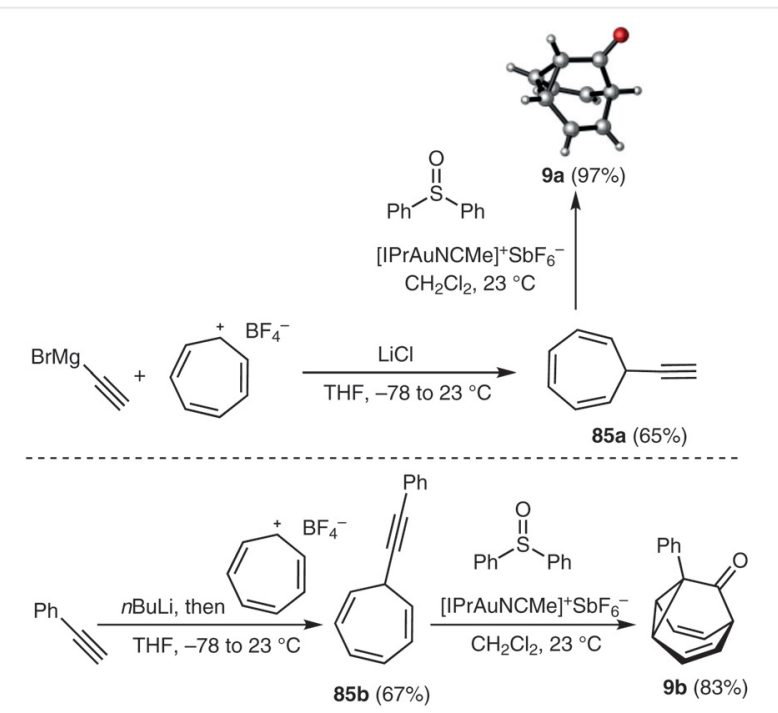

Scheme 29 Synthesis of barbaralone and phenylbarbaralone 
provided barbaralone (9a) and phenylbarbaralone (9b) in $97 \%$ and $83 \%$ yield, respectively. ${ }^{35}$

Bullvalone (10a) and phenylbullvalone (10b) were obtained in $37 \%$ and $22 \%$ yield, respectively through one-carbon homologation of the corresponding barbaralones $9 a$ and 9b using diazo(trimethylsilyl)methane instead of explosive diazomethane employed in classic strategies (Scheme 30). ${ }^{36}$

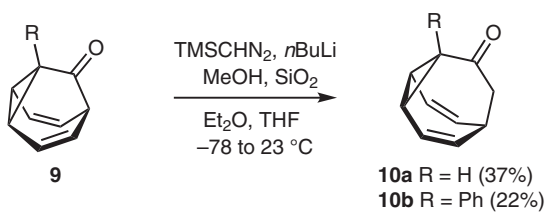

Scheme 30 Preparation of bullvalones by homologation of barbaralones

Bullvalene (1) and phenylbullvalene (27) were prepared from the corresponding bullvalones $\mathbf{1 0 a}$ and $\mathbf{1 0 b}$ via a twostep, one-pot procedure involving the formation of the enol triflates 86 and 87 and subsequent reduction under palladium catalysis in the presence of $n \mathrm{Bu}_{3} \mathrm{SnH}$ (Scheme 31). ${ }^{37}$ This strategy allowed the preparation of bullvalene (1) and phenylbullvalene (27) in 5 steps and $10 \%$ and $7 \%$ overall yield, respectively, constituting one of the most efficient synthesis of these fluxional molecules to date. Moreover, disubstituted bullvalenes $\mathbf{4 5}, \mathbf{8 8}$, and $\mathbf{8 9}$ bearing two equal or two different groups were synthesized from phenylbullvalone (10b) by formation of the enol triflate followed by Stille coupling. ${ }^{38}$ Bullvalenes $\mathbf{4 5}, \mathbf{8 8}$, and $\mathbf{8 9}$ were found to be in $7.6: 5.7: 1,5.2: 1.5: 1,3.8: 2.3: 1$ equilibria, respectively, with the 3,6- and 3,7-disubstituted isomers at $-40{ }^{\circ} \mathrm{C} .{ }^{35}$

The latest synthesis of bullvalene (1) from 2018, as well as several mono- and disubstituted derivatives of $\mathbf{1}$, has been achieved in just two steps and good overall yields by the Fallon and Pašteka groups. ${ }^{39}$ This synthesis is based on a cobalt-catalyzed [6+2] cycloaddition of cyclooctatetraene (2) with terminal or internal alkynes to afford products 8 (Scheme 32), previously encountered as intermediates in the synthesis of bullvalenes (see Schemes 5 and 10). UV irradiation of compounds $\mathbf{8}$ provided a wide range of bullvalenes in good yields, featuring substituents such as alcohols, alkyl, benzyl, and silyl groups. Bullvalene (1) was obtained in $60 \%$ yield over two steps. This procedure constitutes the shortest and most efficient synthesis of bullvalene and mono- and disubstituted bullvalenes to date. Nevertheless, this protocol does not enable the formation of aryl-substituted bullvalenes.

Interestingly the first ${ }^{4 a}$ and the most recent ${ }^{39}$ synthesis of bullvalene (1) are conceptually very similar, although after more than fifty years of research, the overall yield has been increased considerably and the most recent approach is much more versatile.

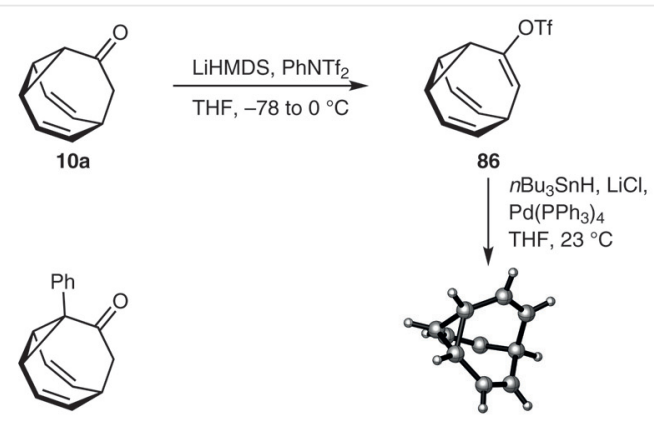

$10 \mathrm{~b}$

1 (44\%, 2 steps)

$\downarrow \begin{aligned} & \text { LDA, 5-CIPyNTf } \\ & \text { THF, }-78 \text { to } 0{ }^{\circ} \mathrm{C}\end{aligned}$
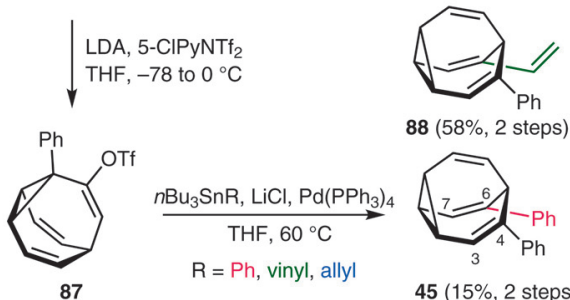

88 (58\%, 2 steps)

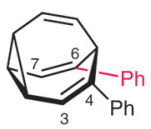

45 (15\%, 2 steps)
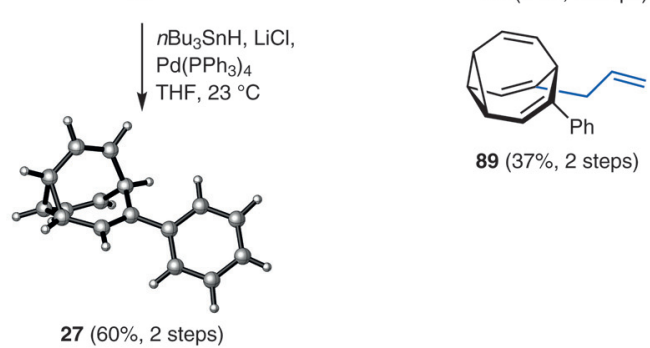

$89(37 \%, 2$ steps $)$

$27(60 \%, 2$ steps $)$

Scheme 31 Synthesis of bullvalene and substituted bullvalenes

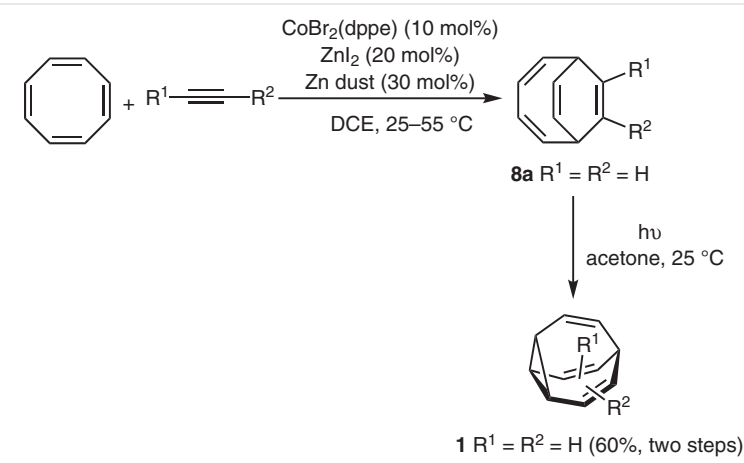

Scheme 32 Most recent synthesis of bullvalene and substituted bullvalenes

\section{Applications of Bullvalenes}

Schröder and co-workers reported the application of crown ether functionalized bullvalenes in the selective binding of metal ions. ${ }^{40,33 d}$ This approach relied on the shapeshifting ability of bullvalenes and the low preference of crown ether substituents for a specific site on the bullvalene core. It was proposed that the crown ether group at- 
tached to bullvalene would adopt different ring sizes as the bullvalene core interconverts into its possible constitutional isomers through Cope rearrangements, leading to selective binding of metal ions depending on their size. Nonetheless, only weak host-guest interactions were observed, leading to low selectivity in the accommodation of different alkali and ammonium cations of distinct sizes (Scheme 33).

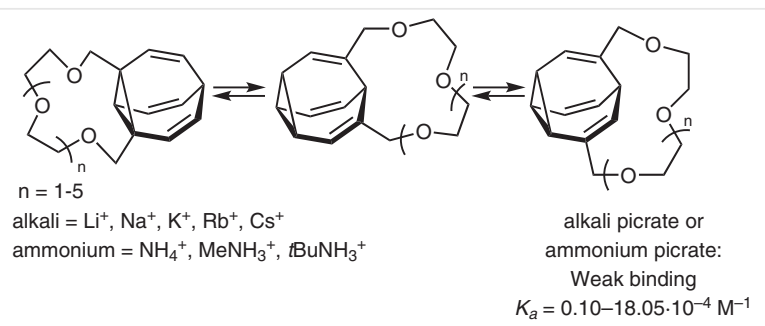

Scheme 33 Application of crown ether substituted bullvalene towards the binding of metal cations

The Bode group has described interesting applications of tetrasubstituted bullvalenes in host discovery. ${ }^{9 b, 33 a, b}$ These studies revealed that due to their shapeshifting nature, these tetrasubstituted bullvalenes could respond and adapt their shapes in order to bind suitable guests. In front of a favorable interaction with a molecular guest, such as $\mathrm{C}_{60}$, the equilibrium of bullvalene constitutional isomers was shifted towards the amplification of the isomers that are more tightly bound to the target, acting as dynamic combinatorial libraries. Moreover, boronic acid substituted bullvalenes with a ${ }^{13} \mathrm{C}$ label have been employed in chemical sensing of polyols such as carbohydrates, flavanols, and sialic acids through covalent binding. ${ }^{33 \mathrm{c}}$ These shapeshifting substituted bullvalenes adapt their structures to strongly bind polyols. Thus, distinct ${ }^{13} \mathrm{C}$ NMR patterns were observed for each polyol bound bullvalene isomer, allowing specific analyte detection by a single NMR measurement (Scheme 34).

\section{Conclusion}

In summary, since the prediction of the structure and properties of bullvalene (1) in 1963 by von Doering several different approaches for the preparation of this unique fluxional molecule have been developed. Most classical syntheses of bullvalene (1) rely on long linear sequences with low overall yields. Nevertheless, these procedures constituted the base for the preparation of a wide variety of substituted bullvalenes, leading to numerous NMR studies on their dynamic fluxional behavior and isomer composition. The constant evolution and enormous advances in synthetic organic chemistry, to which organometallic
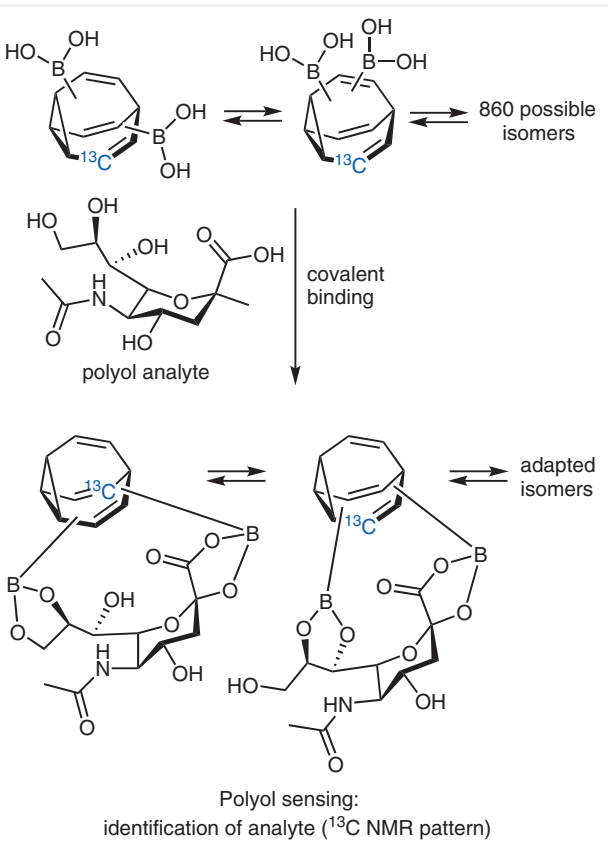

Scheme 34 Application of boronic acid substituted bullvalene in polyol sensing

chemistry has contributed considerably, have enabled the development of expedient synthesis of bullvalenes and substituted derivatives with improved overall yields and less number of steps. The most efficient synthesis of bullvalenes to date are, thus, the most recent ones, featuring $\mathrm{Au}(\mathrm{I}) \mathrm{-}^{35}$ and $\mathrm{Co}(\mathrm{II})$-catalyzed ${ }^{39}$ reactions as key steps. These new synthetic developments, which have streamlined the preparation of a wide range of substituted derivatives, will allow the discovery of new applications for bullvalenes in adaptive binding and sensing. ${ }^{33}$

\section{Funding Information}

This work has been supported by Agencia Estatal de Investigación (CTQ2016-75960-P MINECO/AEI/FEDER, UE), AEI-Severo Ochoa Excellence Accreditation 2014-2018 (SEV-2013-0319), the MEC (FPU fellowship to S. F.), the European Research Council (Advanced Grant No. 321066), the AGAUR (2017 SGR 1257), the CERCA Program/Generalitat de Catalunya and the ICIQ Foundation.

\section{References}

(1) Cotton, F. A. Acc. Chem. Res. 1968, 1, 257.

(2) (a) Doering, W. v. E.; Roth, W. R. Angew. Chem., Int. Ed. Engl. 1963, 2, 115; Angew. Chem. 1963, 75, 27. (b) Williams, R. V. Chem. Rev. 2001, 101, 1185. (c) Hrovat, D. A.; Brown, E. C.; Williams, R. V.; Quast, H.; Borden, W. T. J. Org. Chem. 2005, 70, 1627. (d) He, M.; Bode, J. W. Proc. Natl. Acad. Sci. U. S. A. 2011, $108,14752$. 
(3) (a) Doering, W. v. E.; Roth, W. R. Tetrahedron 1963, 19, 715. (b) Doering, W. v. E.; Ferrier, B. M.; Fossel, E. T.; Hatenstein, J. H.; Jones, M. Jr.; Klumpp, G.; Rubin, R. M.; Saunders, M. Tetrahedron 1967, 23, 3943.

(4) (a) Schröder, G. Angew. Chem., Int. Ed. Engl. 1963, 2, 481; Angew. Chem. 1963, 75, 722. (b) Schröder, G. Chem. Ber. 1964, 97, 3140. (c) Merényi, R.; Oth, J. F. M.; Schröder, G. Chem. Ber. 1964, 97, 3150. (d) Schröder, G.; Oth, J. F. M.; Merényi, R. Angew. Chem., Int. Ed. Engl. 1965, 4, 752; Angew. Chem. 1965, 77, 774.

(5) Saunders, M. Tetrahedron Lett. 1963, 4, 1699.

(6) (a) Poupko, R.; Zimmermann, H.; Luz, Z. J. Am. Chem. Soc. 1984, 106, 5391. (b) Maeir, B. H.; Earl, W. L. J. Am. Chem. Soc. 1985, 107, 5553. (c) Luger, P.; Roth, K. J. Chem. Soc., Perkin Trans. 2 1989, 649. (d) Titman, J. J.; Luz, Z.; Spiess, H. W. J. Am. Chem. Soc. 1992, 114, 3765. (e) Schlick, S.; Luz, Z.; Poupko, R. J. Am. Chem. Soc. 1992, 114, 4315.

(7) (a) Poupko, R.; Zimmermann, H.; Müller, K.; Luz, Z. J. Am. Chem. Soc. 1996, 118, 7995. (b) Müller, K.; Zimmermann, H.; Krieger, C.; Poupko, R.; Luz, Z. J. Am. Chem. Soc. 1996, 118, 8006. (c) Poupko, R.; Müller, K.; Krieger, C.; Zimmermann, H.; Luz, Z. J. Am. Chem. Soc. 1996, 118, 8015. (d) Luz, Z.; Olivier, L.; Poupko, R.; Müller, K.; Krieger, C.; Zimmermann, H. J. Am. Chem. Soc. 1998, 120, 5526.

(8) (a) Volkmann, B.; Schröder, G. Chem. Ber. 1984, 117, 2226. (b) Rebsamen, K.; Schröder, G. Chem. Ber. 1993, 126, 1425.

(9) (a) Lippert, A. R.; Kaeobamrung, J.; Bode, J. W. J. Am. Chem. Soc. 2006, 128, 14738. (b) Lippert, A. R.; Keleshian, V. L.; Bode, J. W. Org. Biomol. Chem. 2009, 7, 1529. (c) Larson, K. K.; He, M.; Teichert, J. F.; Naganawa, A.; Bode, J. W. Chem. Sci. 2012, 3, 1825. (d) He, M.; Bode, J. W. Org. Biomol. Chem. 2013, 11, 1306.

(10) Oth, J. F. M.; Müllen, K.; Gilles, J.-M.; Schröder, G. Helv. Chim. Acta 1974, 57, 1415.

(11) Ault, A. J. Chem. Educ. 2001, 78, 924.

(12) Doering, W. v. E.; Rosenthal, J. W. J. Am. Chem. Soc. 1966, 88, 2078.

(13) Jones, Jr. M.; Scott, L. T. J. Am. Chem. Soc. 1967, 89, 150.

(14) (a) Akiyoshi, S.; Matsuda, T. J. Am. Chem. Soc. 1955, 77, 2476. (b) Phillips, D. D. J. Am. Chem. Soc. 1955, 77, 5179. (c) Bangert, K. F.; Boekelheide, V.J. Am. Chem. Soc. 1964, 86, 905. (d) Bangert, K. F.; Boekelheide, V.J. Am. Chem. Soc. 1964, 86, 1159. (e) Jones, M.; Scott, L. T. J. Am. Chem. Soc. 1970, 92, 3118.

(15) (a) Lambert, J. B. Tetrahedron Lett. 1963, 4, 1901. (b) Barborak, J. C.; Chari, S.; Schleyer, P. v. R. J. Am. Chem. Soc. 1971, 93, 5275. (c) Nakanishi, H.; Yamamoto, O. Chem. Lett. 1975, 513. (d) Engdahl, C.; Ahlberg, P. J. Am. Chem. Soc. 1979, 101, 3940.

(16) Johnston, E. R.; Barber, J. S.; Jacomet, M.; Barborak, J. C. J. Am. Chem. Soc. 1998, 120, 1489.

(17) Font, J.; López, F.; Serratosa, F. Tetrahedron Lett. 1972, 13, 2589.
(18) Stetter, H.; Stark, H. Chem. Ber. 1959, 92, 732.

(19) Shapiro, R. H.; Heath, M. J. J. Am. Chem. Soc. 1967, 89, 5734.

(20) Casas, J.; Serratosa, F. An. Quim. 1977, 73, 300.

(21) Schröder, G.; Oth, J. F. M. Angew. Chem., Int. Ed. Engl. 1967, 6, 414.

(22) Oth, J. F. M.; Merényi, R.; Nielsen, J.; Schröder, G. Chem. Ber. 1965, 98, 3385.

(23) Oth, J. F. M.; Merényi, R.; Rottele, H.; Schröder, G. Chem. Ber. 1967, 100, 3538.

(24) Rebsamen, K.; Röttele, H.; Schröder, G. Chem. Ber. 1993, 126, 1429.

(25) Rebsamen, K.; Röttele, H.; Schröder, G. Chem. Ber. 1993, 126, 1419.

(26) Hoogzand, C.; Nielsen, J.; Oth, J. F. M. Tetrahedron Lett. 1970, 11, 2287.

(27) Oth, J. F. M.; Machens, E.; Röttele, H.; Schröder, G. Justus Liebigs Ann. Chem. 1971, 745, 112.

(28) Oth, J. F. M.; Merényi, R.; Engel, G.; Schröder, G. Tetrahedron Lett. 1966, 7, 3377.

(29) Sarma, K.; Schröder, G. Chem. Ber. 1984, 117, 633.

(30) Vogel, E.; Grimme, W.; Meckel, W.; Riebel, H. J.; Oth, J. F. M. Angew. Chem., Int. Ed. Engl. 1966, 5, 590; Angew. Chem. 1966, 78, 599.

(31) Krüerke, U. Angew. Chem., Int. Ed. Engl. 1967, 6, 79; Angew. Chem. 1967, 79, 55.

(32) Sarma, K.; Witt, W.; Schröder, G. Chem. Ber. 1986, 119, 2339.

(33) (a) Lippert, A. R.; Naganawa, A.; Keleshian, V. L.; Bode, J. W. J. Am. Chem. Soc. 2010, 132, 15790. (b) Zhao, Y.; Yeung, Y. Y. Org. Lett. 2010, 12, 2128. (c) Teichert, J. F.; Mazunin, D.; Bode, J. W. J. Am. Chem. Soc. 2013, 135, 11314. (d) Shapeshifting molecules: synthesis, properties and applications of tetrasubstituted bullvalenes; He, M. Doctoral Thesis: ETH Zürich, 2014.

(34) (a) Jiménez-Núñez, E.; Echavarren, A. M. Chem. Rev. 2008, 108, 3326. (b) Dorel, R.; Echavarren, A. M. Chem. Rev. 2015, 115, 9028. (c) Dorel, R.; Echavarren, A. M. J. Org. Chem. 2015, 80, 7321.

(35) Ferrer, S.; Echavarren, A. M. Angew. Chem. Int. Ed. 2016, 55, 11178; Angew. Chem. 2016, 128, 11344.

(36) Liu, H.; Sun, C.; Lee, N.-K.; Henry, R. F.; Lee, D. Chem.-Eur. J. 2012, 18, 11889.

(37) Scott, W. J.; Stille, J. K. J. Am. Chem. Soc. 1986, 108, 3033.

(38) Scott, W. J.; Crisp, G. T.; Stille, J. K. J. Am. Chem. Soc. 1984, 106, 4630.

(39) Yahiaoui, O.; Pašteka, L. F.; Judeel, B.; Fallon, T. Angew. Chem. Int. Ed. 2018, 57, 2570; Angew. Chem. 2018, 130, 2600.

(40) (a) Schröder, G.; Witt, W. Angew. Chem., Int. Ed. Engl. 1979, 18, 311. (b) Sarma, K.; Witt, W.; Schröder, G. Chem. Ber. 1983, 116, 3800 . 